\title{
Fuzzy Model for Diagnosis of Bacterial Meningitis
}

\author{
Dr. Oye, N. D. \\ Department of Computer Science \\ MAUTECH- Yola Nigeria
}

\author{
Thomas, L. L. \\ Department of Computer Science ADSU, \\ Mubi- Nigeria
}

\begin{abstract}
Over the years, medical field has been one of the different areas where Artificial Intelligence methods were used in order to automate and improve its efficacy and precision. Insufficiency of medical specialist, fatigue, diagnosis error and several level of uncertainties or imprecision in the diagnosis of diseases are some of the factors affecting medical health delivery. Delaying patients with serious diseases like Meningitis may lead to loss of life. There is need for a system that will complement the effort of the medical personnel. This research simulates a fuzzy model for the diagnosis of Bacterial Meningitis using MATLAB R2015a. Symptoms of Meningitis were collected from the domain expert as input to the system, Triangular membership function was used to indicate the degree of membership of each input variable, the type of inference used was Mamdani while for defuzzification, centroid defuzzification method was used. The output of the system is presented on a surface viewer. A mathematical model was also developed. This research was implemented using Microsoft visual studio 2015 and C\# while MSSQL sever management studio 2012 was used for the knowledge base. The outcome of a diagnosis is either present or absent. Records of diagnosed patients are reported in a graphical form in three categories; By Location, Gender and Age for easy analysis.
\end{abstract}

Keywords: Bacterial; Diagnosis; Fuzzy Logic; Fuzzy Model; Meninggitis

\section{INTRODUCTION}

There is increasing death of patients suffering from various diseases in most developing countries due to inadequate medical specialist. The insufficiency of medical specialist may not be overcome within a short period of time as students have to graduate to become doctors and thereafter specialists. While waiting to have a good number of specialist to consult, patients suffering from high risk diseases may already die, spread out the disease or sustained life-time damage. The use of computer technology could reduce the number of mortality and time waiting to see the specialist. Special software's or computer programs were developed by imitating human intelligence in order to assist the doctors in decision making without directly consulting the specialist (Wan et al, 2017).

Health care service delivery has witness an unprecedented opportunities since the emergence of information technology (IT) as modern medical practices become more knowledge-intensive, there is increasing demand for intelligent and knowledge based systems. There are several levels of uncertainties and imprecision in the diagnoses of diseases. The numerous variables involved in the diagnosis and management of diseases makes it complex because of the imprecision and uncertainties. It is hard for a patient to exactly describe how they feel, it is difficult for nurses and doctors to tell what they observe exactly and laboratory results may contain some errors caused by either malfunctioning of the instruments or carelessness of the technician (Djam, Wajiga, Kimbi and Blamah, 2011).

Over the years, medical field has been one of the different areas where Artificial Intelligence methods were used. In order to automate and improve its efficacy and precision, numerous technologies, Models and algorithms are designed. A branch of Artificial Intelligence called Fuzzy Logic is one of such technologies. Decision Support Systems (DSSs) such as Aaphelp, Internist I, Mycin, Emycin, Casnet/Glaucoma, Pip, Dxplain, Quick Medical 
Reference, Isabel, Refiner Series System and PMA have been designed using different models to support medical practitioner in disease diagnosis and treatment (Ahmed et al, 2011)

An expert system is a computer program that represents and reasons with knowledge of some specialist subject with a view to solving problems or giving advice (Josephine and Jeyabalaraja, 2012).

It has been verified that fuzzy logic is one of the effective methods used to bring clarity in the world of medicine. Fuzzy models were used in many areas of medical applications such as in CADIAG, MILORD, DOCTORMOON and MDSS. Automated systems based on fuzzy logic have been used widely in control systems, household appliances, decision making systems and automobile industries (Awotunde, Matiluko \& Fatai, 2014).

Meningitis is defined as an inflammation of the protective membranes that surround the brain and spinal column in particular the arachnoid and pia mater (Bloch and Tang, 2011). At first Vieusseux discovered Meningococcal Meningitis in 1805 during an outbreak with 33 deaths in the vicinity of Geneva, Switzerland, though it wasn't until 1887 that the causative agent was identified by Anton Weichselbaum. Neisseria intracellularis was the name given to it due to its intracellular oval micrococci nature of the organism (Manchanda, 2006). Due to the characteristics of the bacterium and its close relation to Neisseria gonorrhoeae, it was placed in the Neisseria genus and later named Neisseria Meningitidis (Krysta, 2017).

Bacterial meningitis is the most prevalent type of meningitis. It is a pyogenic infection of the meninges. The most common agents of bacterial meningitis are Haemophilus influenzae type b, Neisseria meningitidis, serogroups A, B, C, W135 and Y, and Streptococcus pneumoniae. Although other bacteria may be implicated particularly Neonatal Meningitis. Neonates are prone to getting bacterial meningitis possibly due to the immaturity of their immune system (Arslan, 2012).

The disease can be infectious or noninfectious in origin. The cause of the disease determines the severity. Causes of infectious meningitis are bacteria, viruses, mycobacteria, parasites and fungi while the noninfectious causes of meningitis include inflammatory diseases like sarcoidosis, systemic lupus erythematous, cancer like leukaemia, drugs, head injury and brain surgery. From the above listed, bacterial meningitis is the most severe and it causes significant morbidity and mortality in the world while the viral meningitis is the most common (Kajal, 2014).

In Africa, the first outbreak reported in 1840 was among French troops based in Algiers and during the latter half of the century several outbreaks occurred in Egypt and the Sudan. However, the first major epidemic reported in West Africa was in 1905, while in Nigeria an outbreak with 32 cases of epidemic meningitis in Zungeru, Northern Nigeria was reported. There was a widespread of the outbreak in which further cases were soon reported from Yola, nearly 500 miles east of Zungeru (Brain, 2006). From 13 December 2016 to 14 May 2017, a total of 13,943 suspected cases and 1,112 deaths of meningitis have been reported from 24 States in Nigeria. Sokoto State was one of the hardest hit by the outbreak (WHO, 2017).

\section{Statement of problem}

Medical diagnosis is a complex process which requires clinical skill to arrive at. However, the need for clear decision has to be balanced by an acceptance of the ambiguity of many clinical situations. Experiences and talent of the physician determines the quality of the diagnosis. According to Graber (2013), the general incidence of diagnostic error is in the range of $10 \%$ to $15 \%$. This is due to inaccuracy, imprecision and delay which causes many life. Fatigue and emotional problems degrades the performance of a doctor, it is difficult for medical practitioners to exactly detect the predefined ailment (such as Meningitis) given that laboratory results are prone to man-made or technical errors (Djam, Wajiga, Kimbi and Blamah, 2011). In a report by Suleiman (2016), 
Diagnosis errors are not only the most common medical errors, but they also represent the most dangerous of medical mistakes. Medical error of physician's diagnosis in Nigeria is 69.4\% (Gabriel, et al, 2017). The Nigeria Centre for Disease Control (2017) reports that; from 13th December, 2016 to 8th May, 2017, there were 13,420 suspected cases of Meningitis, total sample tested was 897, 448 cases were confirmed and 1069 deaths (8\%) was recorded. The insufficient number of doctors is due to the expensive and lengthy nature of their training. In Nigeria, the ratio of doctor-to-patient is 1:6000 as against recommended standard of 1:600 (Olawale and Orogun, 2017).

\section{Aim and Objectives of the study.}

The research simulates an expert system for the diagnosis of Bacterial Meningitis using fuzzy logic. The following are the objectives:

i. To identify the necessary input variables required to determine the existence of bacterial meningitis in a patient through data collection techniques such as interview.

ii. To develop a mathematical model for diagnosis of Bacterial Meningitis.

\section{Significance of the study.}

This research work will be significant for all medical personnel, inpatients and outpatients and to the entire populace. It will assist in early detection of bacterial meningitis; improve the quality of medical services where there are insufficient doctors, assist medical personnel when faced with fatigue, tedious and complex challenge. The system will reduce workload on medical personnel by diagnosing and suggesting the appropriate therapy to patients as well as reduce delay in diagnosis. It will reduce mortality rate.

\section{Definition of Operational Terms}

Knowledge-based is a system that constitutes of the problem-solving rules, facts, or intuition that a human expert might use in solving problems in a given problem domain.

Fuzzification: is the process of changing a real scalar value into a fuzzy value.

Defuzzification is the process of translating the output from the inference engine into crisp output.

Linguistic variable are variables whose values are words or sentences in a natural or artificial language.

Inference engine is a computer program that tries to derive answers from a knowledge base.

Fuzzy Logic: is a form of multi-valued logic derived from fuzzy set theory to deal with approximate reasoning.

\section{LITERATURE REVIEW}

Fuzzy logic is been preferred by Researchers because of its ability in handling obscurity in the related problems, flexible structure and use of intuitive methods instead of specific algorithm (Yilmaz, 2015). This logic has been widely used to interpret uncertain knowledge present in a system which may include vague human assessment in problems that are not considered in any conventional computing methods (Banerjee et al, 2016). A lot of researchers have used fuzzy logic to design expert systems for diagnosis of different diseases (Mamta, 2016) but not much has been done on Bacterial Meningitis.

Fuzzy logic has speedily become one of the most successful of today's technologies for developing complex control systems. This is because fuzzy logic addresses such applications perfectly as it resembles human decision making with an ability to generate precise solutions from certain or approximate information (Mankar and Nagdeve, 2014). 


\section{Fuzzy set theory}

Description of the concept of fuzziness by Zadeh (1975) includes imprecision, uncertainty and degree of truthfulness of values. In Fuzzy set theory, Linguistic variables are used for system input and output, and are represented by words such as "temperature", "size" and "age". A fuzzy set is created to describe linguistic variables in more detail. The linguistic variable "temperature", for instance, may have categories (members) of "very cold", "cold", "moderate", "warm", and "very hot". Once these categories or members are defined, the fuzzy set is obtained, and a membership function is then developed for each member in the set.

Fuzzy sets were derived by generalizing the concept of set theory. Fuzzy sets can be thought of as an extension of classical sets. In a classical set (or crisp set), the objects in the set are called elements or members of the set. An element $x$ belonging to a set $A$ is defined as $x \in A$ an element that is not a member in $A$ is noted as $x \notin A$. $A$ characteristic function or membership function $\mu_{\mathrm{A}}(x)$ is defined as an element in the universe $\mathrm{U}$ having a crisp value of 1 or 0 . For every $x \in \mathrm{U}$,

$$
\mu_{A}(x)= \begin{cases}1 & \text { if } x \in A \\ 0 & \text { if } x \notin A\end{cases}
$$

This can also be expressed as $\mu_{A}(x) \in\{0,1\}$

\section{Diagnosis of Malaria born infectious disease.}

Malaria is a mosquito-born infectious disease affecting humans. The damaging effects of malaria parasites to humans cannot be underrated. The existence of Malaria in Africa poses a great treat to so many communities. The concept of Fuzzy Logic offers divers methods of solving problems. In a bid to solve the persistent tropical problem of malaria parasite, Djam, Wajiga, Kimbi and Blamah, (2011), designed a fuzzy expert system for the management of malaria (FESSMM) to offer a decision support platform to physicians and other health practitioners using Root Sum Square (RSS) for fuzzy inference, triangular membership function for degree of participation and Center of Gravity (COG) for defuzzification. In a similar vein, Awotunde, Matiluko and Fatai (2014), developed medical diagnosis system for malaria using fuzzy logic in Visual Prolog Programming language while Priynka, Singh, Manoj and Nidhi (2013) designed a Decision Support System for Malaria and Dengue Disease Diagnosis (DSSMD). The system design based on symptoms explored by Para- medical human resources and patients using MATLAB's graphical user interface. The three different methods each yielded a desired result.

\section{Heart related Fuzzy Models}

The term cardiovascular diseases also known as Heart diseases refer to a variety of ailments that affect the heart as well as all of the blood vessels in the body. Atherosclerosis is one of these ailments, and is caused by a buildup of plaque in a person's arteries; this buildup can accumulate to the point that a clot forms and clogs the artery completely, leading to either a stroke or a heart attack (Kelley, 2014). One of the ways to handle uncertainty in diagnosing heart diseases is by using Fuzzy Petri Nets fuzzy rule and modeling reasoning operation (Lafta and Oleiwi, 2017). Heart disease is the number one killer of human community which can also be diagnosed using Advanced Fuzzy resolution Mechanism. Though Senthil, (2013) made use of Sugeno fuzzy model in his work, Smita, Sushi and Ali (2013) took a different approach to explore the capabilities and potentialities of fuzzy expert systems for the emulation of thought in a much more general sense although confined to medical diagnosis by developing a mathematical model to predict the risk of heart diseases and to compare with the performance of the 
fuzzy expert system. In a broader way, Heart diseases and kidney damage can be diagnosed by a single system. One person dies every 34 seconds due to cardiovascular diseases in the United States (Mayilvaganan and.Rajeswari, 2014).

The main Risk factors of heart disease may include smoke, cholesterol, blood pressure, diabetes, sex and age. This is because of the many and uncertain risk factors in the heart disease, sometimes heart disease diagnosis are hard for experts. The strict boundary between what is Healthy and what is diseased does not exist, thus distinguishing is uncertain and vague. The existence of so many factors to analyze in order to diagnose heart disease of a patient makes the physician's job difficult. Therefore, experts require and accurate tool that consider these risk factors and certain result in uncertain term (Ali and Mehdi, 2010). One of the possible solutions to circumvent such a lifethreatening problem is to make people more aware of their respective Coronary artery disease risk in advance in order to take preventive measures accordingly (Hassan, Sayed, Khalil, \& Ghany, 2017).

\section{Versatile Fuzzy Models}

The concept of fuzzy logic is widely used in medicine field for prediction, risk analysis, decision support system (diagnosis) of many diseases such as Malaria, Cancer, Asthma, heart diseases diabetes, meningitis etc. Generally, it has been observed that fuzzy logic offer the following advantages: flexible structure, tolerance of imprecise date, it can use intuitive methods instead of a specific algorithm and it is based on natural language (Yilmaz, 2015). There are many areas in which fuzzy logic are applied among which are: engineering (electrical, mechanical, civil, chemical, aerospace, agriculture, computer, geological, industrial, and mechatronics), mathematicians, computer software developers and researchers, natural scientists (biology, chemistry, earth science, and physics) social scientists (economics, management, political science, and psychology), public policy analysts and business analysts. Fuzzy logic has produced numerous real life applications such as facial pattern recognition, air conditioners, washing machines, vacuum cleaners, antiskid braking systems, transmission systems, control of subway systems and unmanned helicopters, knowledge-based systems for multi-objective optimization of power systems, weather forecasting systems, models for new product pricing or project risk assessment, medical diagnosis and treatment plans, and stock trading (Singh, et al, 2013).

Several human diseases can be diagnosed electronically by one expert system. Accompanying the conclusion with an explanation is one of the most important aspects of automated diagnosis, it also remain useful for user acceptance. Quality of the diagnosis performed by the system will be evaluated and the utilities will be adjusted. Santosh, Dipti, and Indrajit (2010). Fuzzy expert system designed to handle details of numerous patients and identify challenge the patient if likely to encounter. Several subsystems with independent intelligent controllers have been designed in order to mitigate complexity of the general system. For the extent of relevance of a specific input to be tested, sensitivity analysis has been carried out. The system gives a good insight bout the various pulmonary diseases by predicting its severity nearly equivalent to that of the medical expert (Krishna, Kalpana and Vijayalakshmi 2013).

\section{Fuzzy Models in Diagnosing Meningitis}

A proposed work on supporting meningitis diagnosis amongst infants and children through the use of Fuzzy Cognitive Mapping (FCM) explores the potential of fuzzy cognitive map to assist in the modeling of meningitis, to support physicians in obtaining accurate diagnosis and treatment of the condition. The method of FCM was used for analyzing and depicting human perception of a given system. A group of four pediatricians, was formed 
to define the multifarious signs and symptoms associated with meningitis and to identify risk factors integral to its causality, and indicators to identify the absent of presence of meningitis in a patient. The results produced by the system are: specificity of $80 \%$ and sensitivity of $83.3 \%$. While Vijay, Ravinder, Ryan and Elpiniki (2012) are using Fuzzy Cognitive Mapping, other researchers like Mostafa, Esmat, Hassan, Mehrdad and Mahdi, (2015) proposed a Fuzzy Expert System for Distinguishing between Bacterial and Aseptic Meningitis in order to avoid unnecessary antibiotic treatments, patient hospitalization, and misdiagnosis of bacterial meningitis. The system uses the software Weka 3.6.7. for proper selection where six attributes were selected using Attribute Evaluator, InfoGainAttributeEval, and Ranker search method items. Then, a fuzzy inference engine was designed using MATLAB software, based on Mamdani's fuzzy logic method with max-min composition, prod-probor, and centroid defuzzification. The system accuracy, specificity, and sensitivity were $89 \%, 92 \%$, and $97 \%$, respectively.

\section{Major symptoms in diagnosing Meningitis.}

\section{Fever}

Fever was defined in 2001 by International Union of Physiological Sciences Commission for Thermal Physiology as "the state of elevated core temperature, which is often, but not necessarily, part of the defensive responses of multicellular organisms (host) to the invasion of live (micro-organisms) or inanimate matter recognized as pathogenic or alien by the host". The body temperature of healthy individuals varies in relation to several biological and environmental factors like place of temperature measurement, time of the day, age, sex, race, and rate of physical activity etc. other things that accompany fever are sickness behaviors, changes in metabolic and physiological characteristics of the body system and alterations in immune responses. Fever can be classified based on height of body temperature as low grade, moderate grade, high grade and hyperpyrexia (Mackowiak, 2005).

Fever can be classified based on height of body temperature as low grade, moderate grade, high grade and hyperpyrexia. There are three major types of fever which are described as sustained/continuous fever, intermittent fever and remittent fever, example of such diseases are typhoid, acute bacterial meningitis and urinary tract infection among others. The fever that is constantly above normal and does not change for more than $1^{\circ} \mathrm{C}$ during 24hours is called sustained or continuous fever. The fever that is only present for several hours during the day is called intermittent fever. Example of this fever pattern is malaria tuberculosis and pyogenic infections among others. Remittent fever is can be defined as the fever whose daily fluctuation exceeds $2^{\circ} \mathrm{c}$ and does not touches normal at any time. This is mostly associated with infectious diseases (Ogoina, 2011). It is observed that the normal body temperature is not a single number, but rather a range of temperatures. However, recent studies indicate that $98.2^{\circ} \mathrm{F}\left(36.8^{\circ} \mathrm{C}\right)$ is a more accurate average (William, 2018). There are varying body temperature values obtained from different researches, some of which are shown below.

\begin{tabular}{lll}
\hline Body temperature & ${ }^{\circ} \mathrm{C}$ & ${ }^{\circ} \mathrm{F}$ \\
\hline Normal & $37-38$ & $98.6-100.4$ \\
Mild/low grade fever & $38.1-39$ & $100.5-102.2$ \\
Moderate grade fever & $39.1-40$ & $102.2-104.0$ \\
High grade fever & $40.1-41.1$ & $104.1-106.0$ \\
Hyperpyrexia $^{\mathrm{a}}$ & $>41.1$ & $>106.0$ \\
\hline
\end{tabular}

Source: (Ogoina, 2011).

$\begin{array}{ll}\text { Body Temperature Chart } \\ \text { Core Measurement (rectal, esophageal, etc.) }\end{array}$
$\begin{array}{lll}\text { Classed as: } & \text { Celsius } & \text { Fahrenheit } \\ \text { Hypothermia } & <35.0^{\circ} \mathrm{C} & 95.0^{\circ} \mathrm{F} \\ \text { Normal } & 36.5-37.5^{\circ} \mathrm{C} & 97.7-99.5^{\circ} \mathrm{F} \\ \text { Fever / Hyperthermia } & >37.5 \text { or } 38.3^{\circ} \mathrm{C} & 99.5 \text { or } 100.9^{\circ} \mathrm{F} \\ \text { Hyperpyrexia } & >40.0 \text { or } 41.5^{\circ} \mathrm{C} & 104.0 \text { or } 106.7^{\circ} \mathrm{F}\end{array}$

Source: https://www.disabled-world.com/ 
Figure 1: Different range of body temperature

\section{Photophobia}

According to Digre and Brennan (2012), photophobia can be defined as a sensory state in which light causes discomfort in the eye or head; it may also cause an avoidance reaction without overt pain. The term Photophobia refers to a sensory disturbance provoked by light. The term photophobia, derived from 2 Greek words, photo meaning "light" and phobia meaning "fear", literally means "fear of light" (Yiwen and Mark, 2017).

The effect of intracranial conditions like meningeal irritation from meningitis, and pituitary tumors cause photophobia. (Kawasaki and Purvin, 2002) due to irritation of the basal meninges especially around the diaphragma sellae. This pain is mediated by branches of the first division trigeminal nerve which innervates the meninges (Digre and Brennan, 2012). So far, there is no much evidence proving that the systematic medication can relive photophobia itself; rather treating the primary condition may improve the associated photophobia. Therefore, pharmacotherapeutic treatment for photophobia remains unknown because the real mechanism of photophobia is still not clear.

\section{Headache}

Headache could be a sign of stress or emotional distress, or it can result from a medical disorder, such as migraine or high blood pressure, anxiety, or depression. Primary headaches are diseases without any underlying organic etiology, which distinguishes them from secondary headaches (Elik and Yurtay, 2017). Generally, Headache is a chronic disease which is largely divided into two classes: primary and secondary. A primary headache is mostly described as common, painful and debilitating disorder that accounts for large number of headache disorders, including the four main categories (Wu, Duana and Duc, 2015). These are: Migraine, Tension-Type Headache (TTH), Cluster or Trigeminal Autonomic Cephalalgias (TACs) and other primary headache disorders (ICHD $3^{\text {rd }}$ edition, 2013).

The vast majority of headache disorders are primary headache with tensiontype (TTH) and migraine headache being most prevalent. TTH affects $60-80 \%$ of the population while migraine has a prevalence of $15 \%$ (male $7.6 \%$, female $18.3 \%$ ). Cluster headache is uncommon (0.1\%) but often misdiagnosed and mismanaged. Medicationoveruse headache (MOH) is a secondary headache disorder and mostly co-exists with primary headache disorders, and is often described with them (Fayyaz, 2012).

A headache could be termed as secondary headache: when a new headache occurs for the first time in close temporal relation to another disorder that is known to cause headache, or fulfills other criteria for causation by that disorder, the new headache is coded as a secondary headache attributed to the causative disorder. Secondary headache may include: Headache attributed to trauma or injury to the head and/or neck, Headache attributed to cranial or cervical vascular disorder, Headache attributed to non-vascular intracranial disorder, Headache attributed to a substance or its withdrawal and Headache attributed to infection among others (ICHD $3^{\text {rd }}$ edition, 2013).

\section{Hypertension}


Hypertension means elevation of arterial blood pressure likely to induce cardiovascular, renal and other problems (Kaur and Bhardwaj, 2014). One of the silent killer diseases is Hypertension, this is due to the fact that it has no specific symptom, and if left untreated it is capable of causing long time problems like heart attack and chronic kidney disease. For improved diagnosis and treatment of hypertension, and accurate and intelligent diagnosis system will be required (Das, Ghosh and Kar, 2013). Hypertension can be categorized as essential or secondary. Essential hypertension is another term for high blood pressure whose cause is unknown. Essential hypertension accounts for about $95 \%$ of cases. Secondary hypertension is the term used for high blood pressure with a known direct cause, such as, birth control pills and kidney disease (Kaur and Kaur, 2014).

\section{Irregular breathing}

Often times, clue of some disease process are detected from the pattern of breathing. Irregular pattern of breathing are mostly caused by injury to respiratory centres in pons and medulla, metabolic derangement, use of narcotic medications and respiratory muscle weakness. Others are anxiety and fever cause an elevation in respiratory rate not associated with respiratory suffering. On the average, a person (adult) takes between 12 to 20 breaths per minute. Rapid, shallow breathing, also called tachypnea, occurs when you take more breaths than normal in a given minute (Yuan, Drost and McIvor, 2013).

Presently, techniques for monitoring breathing can be categorized in to two types: Invasive and Non-invasive. In invasive type, the techniques used include belt or trap to track changes in the circumference during respiratory circle and nasal temperature examination while Noninvasive type uses audio analysis to monitor tidal volumes from human breathing activity, vibration sensor (Wang, Ahmed and Hunter, 2006) and thermal imaging (Murthy Pavlidis and Tsiamyrtzis, 2004).

\section{Neck Stiffness}

Neck stiffness is mostly found in clinical practice accompanying meningeal irritation. The term "neck pain" is used to describe any pain in the region of the neck. Neck pain could be described as "common" when the doctor is unable to identify a specific disorder with a cause, likely outcome, and specific treatment. The term "common neck pain" should not be used to describe symptoms that may be chronic and incapacitating, and which the patient does not regard as trivial. The term "nonspecific" would be more appropriate (Françoise, 2003). The most common musculoskeletal disorder encountered by health care professional on a daily basis after low back pain is Neck pain (Ingram, Snodgrass and Rivett, 2015).

Causes of neck stiffness are:

i. Muscle spasm: The neck movement is controlled by the muscles. When the muscles are injured, the go into spasm.

ii. Join Dysfunction or (Subluxation). The joint(s) stop moving when the special gliding joint that help the neck glide in different direction and positions malfunction.

iii. Meningitis: Meningitis is an inflammation or irritation of the sheath, the bag that surrounds your spinal cord, and sometimes this can be bacterial or even a viral infection of the meninges, and that will cause some neck stiffness (Carvosso, 2018).

\section{Convulsion}

The word convulsion is also referred to as seizure. The excessive nerve-cell discharge in the brain is called Seizure. It is a quick unusual function of the body, mostly with loss of consciousness, excessive muscular activities or sometimes a loss of it or an unusual sensation (Dekker, 2002). A seizure is characterized by aberrant electrical 
activity within the brain. A convulsion is a period of involuntary muscular contraction, often followed by a period lethargy and confusion and sometimes profound sleep. Various reasons for convulsion may include: Epilepsy, Meningitis, Hypoxia, Hypotension, Febrile, Cardiac arrest etc. (Rho, Sankar and Stafstrom, 2010).

Table 1. Profile for Meningitis

\begin{tabular}{|c|c|c|}
\hline $\begin{array}{ll} & \text { Attributes } \\
\text { Features } & \end{array}$ & Low & High \\
\hline Sudden High Fever & May be & Yes \\
\hline Severe Headache & May be & Yes \\
\hline Projectile Vomiting & May be & Yes \\
\hline Loss of consciousness & May be & Yes \\
\hline No appetite or thirst & May be & Yes \\
\hline Reddish or darkish skin rash & No & Yes \\
\hline Confusion or restlessness & No & May be \\
\hline Photophobia & Maybe & Yes \\
\hline $\begin{array}{l}\text { Sign of meningeal irritation (Brudzinki } \\
\text { and Kenings Sign) }\end{array}$ & No & May be \\
\hline Convulsion & No & Yes \\
\hline Hypertension & No & Yes \\
\hline Irregular breathing & No & Yes \\
\hline Slow heart beat (Bradycardia) & No & Yes \\
\hline
\end{tabular}

Upon examining the patient to be diagnosed, the set of his symptoms $\boldsymbol{S}$ would be obtained. A typical example for the set of symptoms is given in the table below which shows fuzzy values for all features in the collective set $\boldsymbol{F}$.

Table 2 Typical symptoms for a given input case.

\begin{tabular}{|l|c|}
\hline Features & $\begin{array}{c}\text { Fuzzy } \\
\text { Value* }\end{array}$ \\
\hline Sudden High Fever & $\mathrm{H}$ \\
\hline Severe Headache & $\mathrm{H}$ \\
\hline Projectile Vomiting & $\mathrm{H}$ \\
\hline Loss of consciousness & $\mathrm{H}$ \\
\hline No appetite or thirst & $\mathrm{H}$ \\
\hline Reddish or darkish skin rash & $\mathrm{L}$ \\
\hline Confusion or restlessness & $\mathrm{L}$ \\
\hline Photophobia & $\mathrm{H}$ \\
\hline Sign of meningeal irritation & $\mathrm{L}$ \\
(Brudzinki and Kenings Sign) & \\
\hline Convulsion & $\mathrm{H}$ \\
\hline Hypertension & $\mathrm{L}$ \\
\hline
\end{tabular}




\begin{tabular}{|l|l|}
\hline Irregular breathing & $\mathrm{L}$ \\
\hline Slow heart beat (Bradycardia) & $\mathrm{L}$ \\
\hline
\end{tabular}

$* H=$ high, and $L=$ low

The above table acts as an interface for the expert physician to gather information from the patient, which is used to interrogate our back-end knowledge-base whose result forms our conclusion (Confirmed disease). The fuzzy set of features is represented by ' $\mathrm{f}$ ', which is defined as $\mathrm{f}=\{\mathrm{fl}, \mathrm{f} 2, \ldots \ldots \ldots \mathrm{fn}\}$ where fi represents the $\mathrm{i}^{\text {th }}$ parameter and $\mathrm{n}$ is the number of parameters.

\section{Fuzzy Inference Engine}

An inference engine is a computer program that tries to derive answers from a knowledge base. It is used in expert systems for the purpose of formulating new conclusions. Fuzzy inputs are mapped into their respective weighting factors and their associated linguistic variables to determine their degree of membership (Olayanju, 2017). Fuzzy rules in the rule base will be evaluated and logical operators such as AND, OR and NOT are applied to combine the weighted consequences of all the relevant antecedents into a single fuzzy set. A number of rules will be generated. The degree of truth will be determined for each rule by evaluating the non-zero minimum values using the AND operator. The inference engine evaluates all the rules in the rules base and combines the weighted consequences of all the relevant (fired) into a single fuzzy set. The inference engine consists of reasoning algorithm.

The inference engine technique is as follows:

Let:

$$
\begin{aligned}
& \mathrm{s}[\mathrm{f}] \quad=\text { fuzzy value for the feature fof the input case's symptoms. } \\
& r_{i j}=j^{\text {th }} \text { relevant feature of the } i^{\text {th }} \text { disease. } \\
& P_{i j}\left[r_{i j}, v\right]=\text { certainty of presence of the } i^{\text {th }} \text { disease when the relevant feature } r_{i j} \text { has a fuzzy } \\
& \text { value } v \text {. } \\
& \delta_{\mathrm{ij}}=\text { diagnosis decision of the } \mathrm{i}^{\text {th }} \text { disease based on the relevant feature } \mathrm{r}_{\mathrm{ij}} \text {. } \\
& \mathrm{k}_{\mathrm{i}}=\text { total number of relevant features for the } \mathrm{i}^{\text {th }} \text { disease. } \\
& \mathrm{w}_{\mathrm{ij}} \quad=\text { weight of the } \mathrm{r}_{\mathrm{ij}} \text { feature in diagnosing the } \mathrm{i}^{\text {th }} \text { disease. } \\
& \sigma_{\mathrm{i}} \quad=\text { overall diagnosis decision for the } \mathrm{i}^{\text {th }} \text { disease. }
\end{aligned}
$$

The effect of the $\mathrm{r}_{\mathrm{ij}}$ feature on the diagnosis decision can be directly obtained from the disease profile table $\mathrm{P}_{\mathrm{ij}}\left[\mathrm{r}_{\mathrm{ij}}\right.$ , v]. The fuzzy value $v$ is obtained from the patient's symptoms for the feature $\mathrm{r}_{\mathrm{ij}}$ as $\mathrm{s}\left[\mathrm{r}_{\mathrm{ij}}\right]$. This effect $\delta_{\mathrm{ij}}$ would be one of the fuzzy sets Yes, May Be, and No. It can be represented as follows:

$$
\delta_{\mathrm{ij}}=\mathrm{P}_{\mathrm{ij}}\left[\mathrm{r}_{\mathrm{ij}}, \mathrm{s}\left[\mathrm{r}_{\mathrm{ij}}\right]\right]
$$

By summing up the effect of all $\mathrm{k}_{\mathrm{i}}$ relevant features, the overall diagnosis decision for the $\mathrm{i}^{\text {th }}$ disease would be obtained as follows: 


$$
\sigma_{i}=\left(\sum_{j=1}^{j=k_{i}} w_{i j} \delta_{i j}\right) /\left(\sum_{j=1}^{j=k_{i}} w_{i j}\right)
$$

The weighting factor $\mathrm{w}_{\mathrm{ij}}$ is introduced here to allow the physician to specify that some features can have more or less significance than others when diagnosing a disease, and he should set proper relative values to the weights. If he considers that all features have the same significance, then the weighting factor will be unity for all features. In this case equation (2) can be simplified to be:

$$
\sigma_{i}=\frac{1}{k_{i}} \sum_{j=1}^{j=k_{i}} \delta_{i j}
$$

The final step is to obtain crisp values specifying the certainty of presence for every disease in the set $\boldsymbol{D}$. To show how to obtain such crisp values, consider the following example.

- Assume that a given disease $d_{i}$ has 10 relevant features, all of which has the same weight in the diagnosis. That is:

$$
\begin{aligned}
& \mathrm{k}_{\mathrm{i}}=10, \\
& \mathrm{w}_{\mathrm{ij}}=1 \quad \text { for all } \mathrm{j}=1, \ldots, 10 .
\end{aligned}
$$

- Assume that when using equation (1) to find out the diagnostic decisions $\left(\delta_{\mathrm{ij}}, \mathrm{j}=1, \ldots, 10\right)$ the result was 7 Yes, 2 May Be, and 1 No.

The overall diagnostic decision will be: $\sigma_{i}=(7$ Yes +2 May Be +1 No $) / 10$

\section{Defuzzification}

Defuzzification is a process of converting the fuzzy output to a crisp value. The input to defuzzification process is a fuzzy set while the output of the defuzzification process is a single number known as crisp output (Angbera, Esiefarienrhe and Agaji I. 2016).

The output from the fuzzy rule is a fuzzy value which must then be defuzzified. Some of the frequently used methods are centroid or centre of area (COA), centre of sums, and mean of maxima. The defuzzification method for this research is centroid.

When using the centroid method of defuzzification, the crisp value $u$ is assumed to be the geometric center of the output fuzzy value $\mu$ OUT $(u)$, where $\mu$ OUT $(u)$ is formed by taking the union of the contributions of all rules that has degree of membership function greater than zero. This method is based on finding the balance point of the whole geometric figure (Zirra, Umar and Wallace, 2016).

The defuzzification out for a discrete universe of discourse is defined as

$$
u=\frac{\sum_{i=1}^{N} \mu_{i} \mu_{\text {OUT }}\left(u_{i}\right)}{\sum_{i=1}^{N} \mu_{\text {OUT }}\left(u_{i}\right)}
$$

\section{Surface viewer of the BMDS.}


The surface viewer displays the output surface of the Bacterial Meningitis Diagnosis system in a graphical interface. It uses a number of input variables to generate the graph.

\section{Neck stiffness and Headache.}

Figure 1 depicts that Meningitis can be determined by Neck Stiffness and Headache. The output highly depends on Neck stiffness accompanied by Headache.

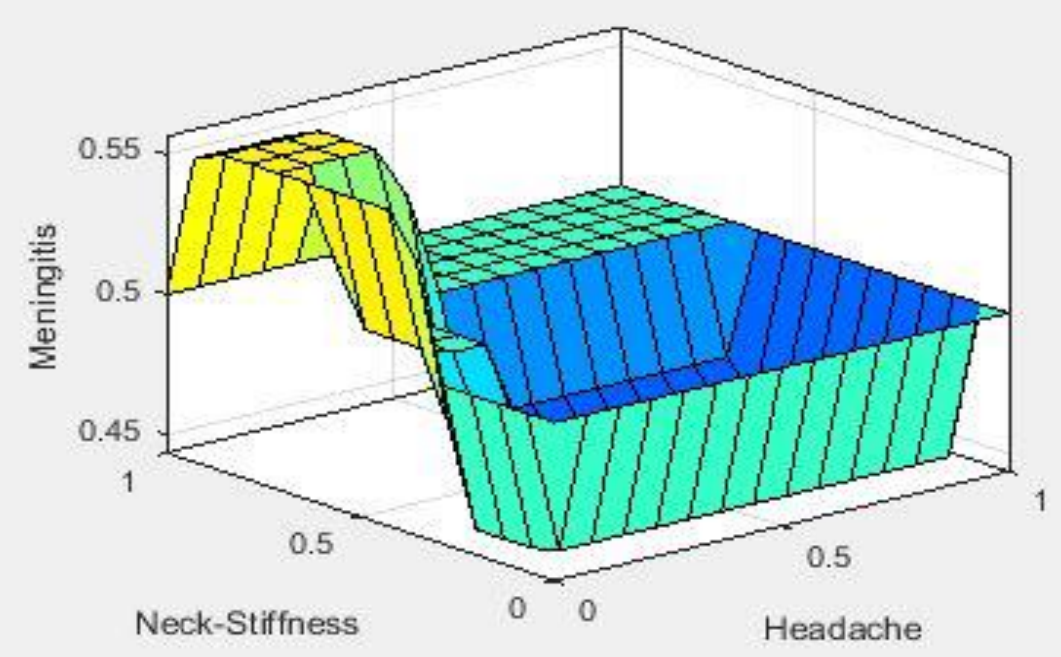

Figure 1: Surface view of Neck stiffness and Headache

\section{Fever and Slow Heart Beat}

Figure 2 indicate the dependency of output variable Meningitis on the input variables Fever and Slow Heart Beat. It clearly depict that determining Meningitis highly depends on both fever and slow heartbeat when considering the two.

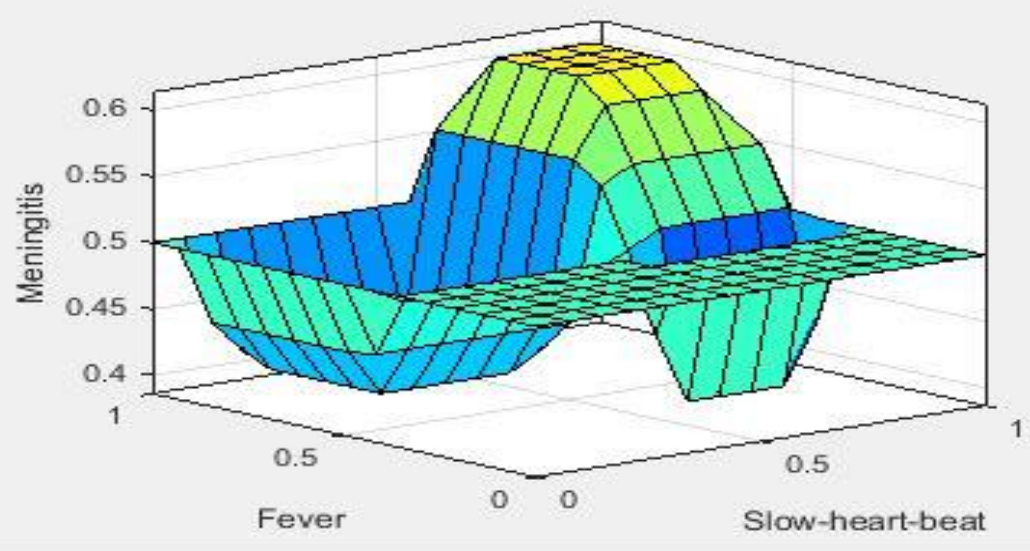

Figure 2: Surface view of Fever and Slow Heart Beat

\section{Headache and Fever}

Figure 3 shows that detecting Meningitis also depends on the input variables Headache and Fever. The output depict that determining Meningitis depends more on Fever with Headache at a severe level.

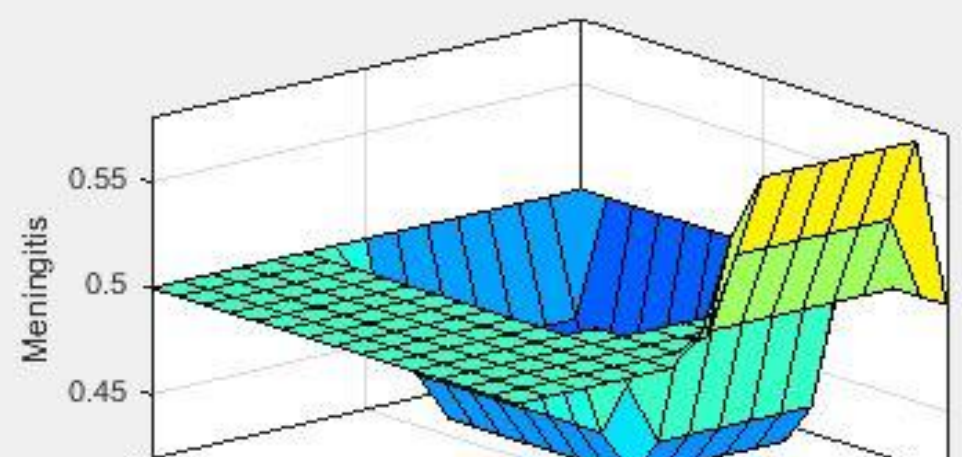


Figure 3 : Surface view of Headache and Fever.

\section{Neck stiffness and Slow Heart Beat.}

Figure 4 shows the dependency of output variable Meningitis on the input variables Neck stiffness and slow hear beat. The output clearly depict that determining Meningitis could also depends highly on both Neck Stiffness and Slow heartbeat.

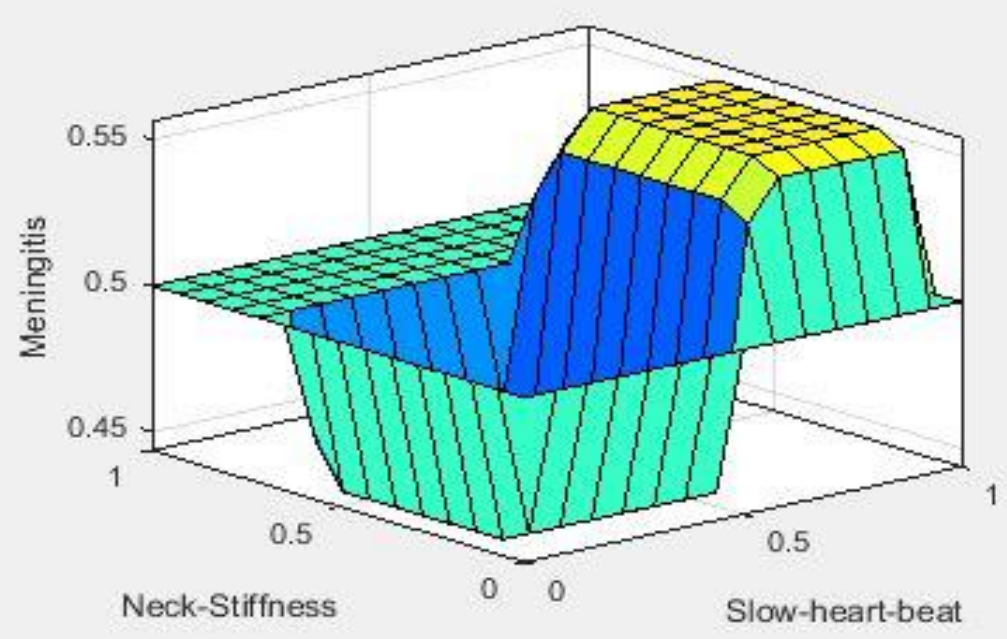

Figure 4: Surface view of Neck Stiffness and Slow Heart Beat.

\section{Fever and Irregular Breathing.}

Figure 5 shows the dependency of output variable Meningitis on the input variables Fever and Irregular Breathing. The output suggests that determining Meningitis also depends on both Fever and Irregular breathing with more dependence on Irregular Breathing having Fever at a severe level.

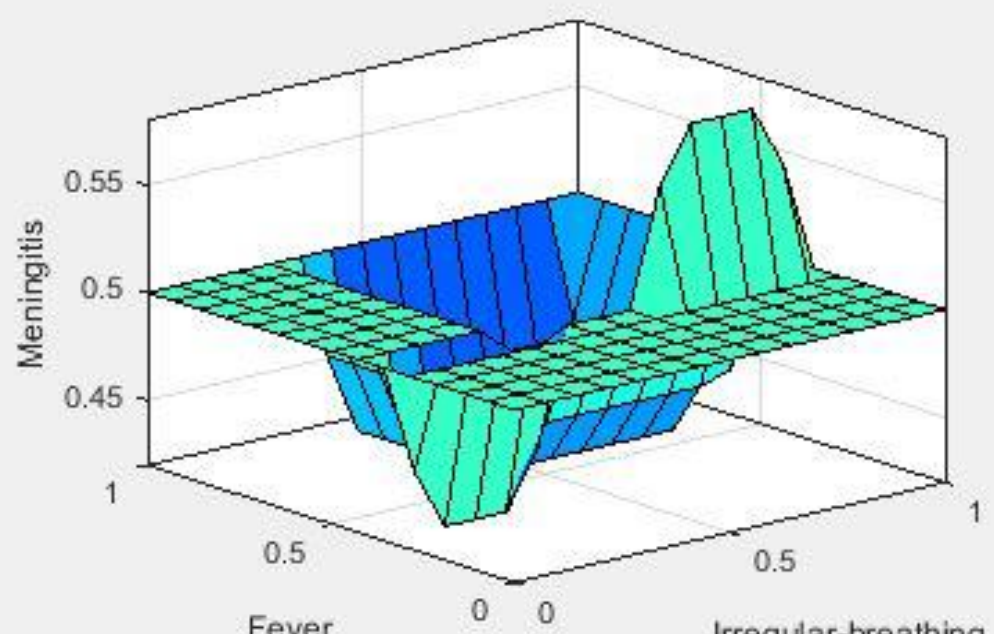


Figure 5: Surface view of Fever and Irregular Breathing.

\section{Slow Heart Beat and Headache.}

Figure 6 shows the dependency of output variable Meningitis on the input variables Slow Heart beat and Headache. The output suggests that determining Meningitis could also depends on both slow heart beat and severe headache with more dependence on slow heartbeat.

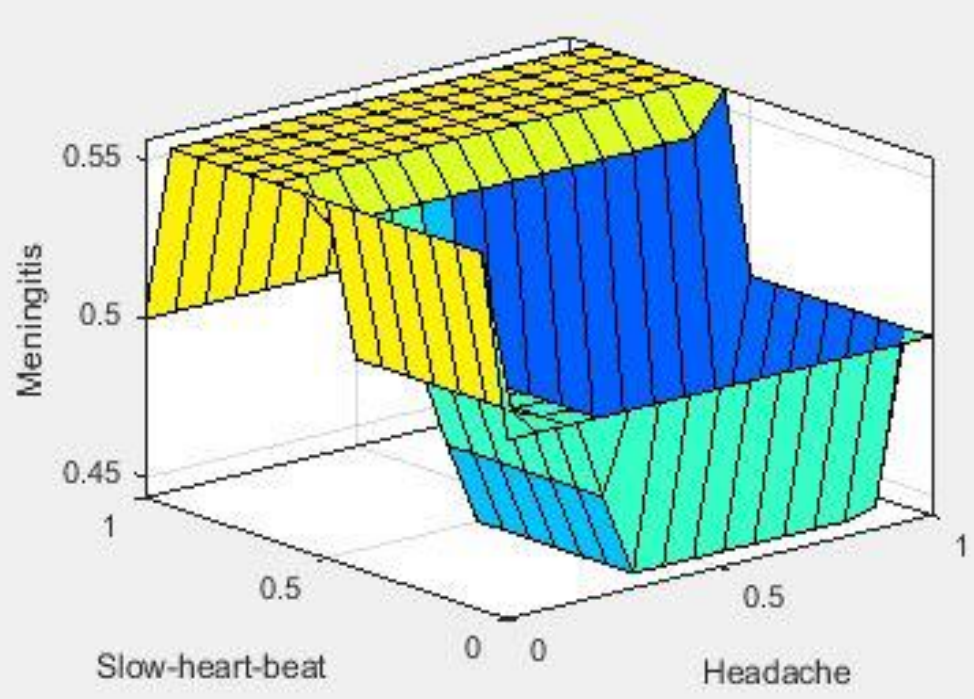

Figure 6: Surface view of Slow-heart-beat and Headache.

In the medical field, cardinal symptoms for diagnosing Bacterial Meningitis are considered in a set of three symptoms. Figures $1-6$ were the simulated results in three-dimension using MATLAB R2015a. It is currently difficult to represent higher dimensions without misrepresenting output figures . in fuzzy logic tool. This is the reason that limited the number of input variables to two against one output variable. However, the functionality of the system was not mired because each factor represented is an essential part of the whole system.

\section{Conclusion}

The modern medical practice is becoming more knowledge-intensive, thus the increasing demand for intelligent and knowledge based systems for more efficient services. The research aimed to simulate and develop an expert system for the diagnosis of Bacterial Meningitis using fuzzy logic tool. Series of activities were carried out by the researcher in order to achieve the said aim. At first, all input variables (symptoms) required to determine the existence of bacterial meningitis in a patient was determined through interview with the domain expert who also determines the membership degree to the system input variables. 
The fuzzy inference system was created and named; Bacterial Meningitis Diagnosis System. The system used triangular membership function. The input variables were fuzzified using triangular fuzzifier and the fuzzy output becomes the inference input. The inference type is Mamdani. Logical AND operator was used to combine the antecedent IF and the consequent THEN (IF-THEN statements) to generate 177 rules that fired to produce output which becomes the input to the defuzzifier. The system uses Centroid deffuzication method and the output of the system is a graph presented on the surface viewer. This presents different graphs based on the input selected.

Mathematical model was developed to determine the presence or absence of Bacterial Meningitis in a patient. Knowledge base component which contains all the relevant data was developed using MSSQL sever management studio 2012. The expert system for the diagnosis was developed using Microsoft visual studio 2015 and C\# object oriented language. Features of the system includes: Home page that has three menus, patients registration page, patients diagnosis page, data page which presents patients record in a tabular form and reports which are graphical representations based on gender, age-group and LGA of residence.

The medical service delivery faces challenges such as insufficiency of medical specialist, diagnosis error and several levels of uncertainties and imprecision in the diagnoses of diseases, thus the need for this research. This research has simulated a fuzzy model for diagnosis of Bacterial Meningitis and implements it as system called Bacterial Meningitis Diagnosis System (BMDS). BMDS will go along-way in helping medical personnel to safe lives of patients suffering from Bacterial Meningitis. BMDS can help the medical personnel to have an automated record of patients, analyze the record and produce reports in a graphical form for easy analysis. The system can be used by any authorized medical personnel or para-medical personnel. 


\section{REFERENCES}

Ahmed A.E.S., Sherif E.B. and Ahmed A.B.A., (2011). A Fuzzy Decision Support System for Management of Breast Cancer, (IJACSA) International Journal of Advanced Computer Science and Applications, Vol. 2, No.3, March 2011.

Ali A. and Mehdi N. (2010), a Fuzzy Expert System for Heart Disease Diagnosis. Proceedings of the International MultiConference of Engineers and Computer Scientist. 2010 Vol. I, IMECS 2010, March 17-19, 2010, Hong Kong. ISBN: 978-988-17012-8-2. ISSN:20178-0958 (print); ISSN: 20780988(online).

Angbera A., Esiefarienrhe M. B., Agaji I. (2016), Efficient Fuzzy-Based System for the Diagnosis and Treatment of Tuberculosis(EFBSDTTB). International Journal of Computer Applications Technology and Research, Volume 5- Issue 2, pp.34 - 48, 2016, ISSN:- 2319-8656

Arslan A., (2012). Etiology of Bacterial meningitis in Ethiopia. Unpublished M.Phil thesis, faculty of Medicine University of Oslo, Ethiopia.

Awotunde J. B, Matiluko O.E and Fatai O.W. (2014). Medical Diagnosis System Using Fuzzy Logic. African Journal of Computing \& ICT Reference Format: Afr J. of Comp \& ICTs. Vol 7, No. 2. Pp 99-106.

Banerjee S, Aishwaryaprajna, Debjani C, Amita G, Ranjan G, Badal C. S, Jyotirmoy C. (2016). Application of fuzzy consensus for oral pre-cancer and cancer susceptibility assessment. Egyptian Informatics Journal (2016) 17, 251-263.

Bloch, K. C. \& Tang., Y.-W. 2011. Molecular Approaches to the Diagnosis of Meningitis and Encephalitis. In: PERSING, D. H. (ed.) Molecular Microbiology:Diagnostic Principles and Practice.2nd ed. Washington D.C.: ASM Press.

Brian G. (2006). Editorial: 100 years of epidemic meningitis in West Africa - has anything changed?. Tropical Medicine and International Health. volume 11 no 6, pp 773-780, June, 2006. doi:10.1111/j.13653156.2006.01639.x

Carvosso B. (2018), Causes of a stiff Neck. Retrieved October 1, 2018 from Mornington Peninsula Chiropractic Centre website: http://mornpenchiro.com.au/wp-content/uploads/Causes-Of-A-Stiff-Neck.pdf

Das S, Ghosh P. K. and Kar S. (2013), Hypertension Diagnosis: A Comparative $\quad$ Study using Fuzzy Expert System and Neuro Fuzzy System. IEEE International Conference on Fuzzy Systems. DOI: 10.1109/Fuzz-Ieee.2013.6622434

Dekker P. A. (2002), Epilepsy: A manual for Medical and Clinical Officers in Africa. Ilae/Ibe/Who Global Campaign Against Epilepsy Achterweg 5, 2103 SW Heemstede, the Netherlands.

Digre K.B. and Brennan K.C. (2012), Shedding light on photophobia. J Neuroophthalmol.2012;32(1): pp 68-81. doi:10.1097/WNO.0b013e3182474548.

Djam, X.Y., Wajiga, G. M., Kimbi Y. H. and Blamah, N.V., (2011). A Fuzzy Expert System for the anagement of Malaria. International Journal of Pure and Applied Sciences and Technology. ISSN 2229 - 6107, 5(2) (2011), pp. 84-108.

Elik U. C. and Yurtay N. (2017), An ant Colony Optimization Algorithm-based Classification for the diagnosis of primary headaches using a website questionnaire expert system. Turkish Journal of Electrical Engineering \& Computer Sciences. 25: 4200 - 4210. doi:10.3906/elk-1612-178.

Fayyaz A. (2012), Headache disorders, differentiating and managing the common subtypes. The British Journal of Pain. 6(3), PP. 124-132. doi: 10.1177/2049463712459691.

FEMA (2005), Decision Making and Problem Solving. FEMA Independent Study Program, Emergency Management Institute, 16825 South Seton Avenue Emmitsburg, MD 21727(301) 447-1200.

Françoise B. (2003), Physiotherapy in common neck pain and whiplash. ANAES, Guidelines Department, 2003, Pp. 1-10. 
Ingram L. A, Snodgrass S. J., Rivett D. A.(2015), Comparison of Cervical Spine Stiffness in Individuals With Chronic Nonspecific Neck Pain and Asymptomatic Individuals. Journal of Orthopaedic \& Sports Physical Therapy, vol.45,(3). Pp. 162 - 169.

Gabriel U. P. I., Abali C., Agwu N. A. (2017). Medical Errors in Nigeria: A Cross- sectional Study of Medical Practitioners in Abia State. Department of Family Medicine, Federal Medical Centre, Umuahia, Abia State, Nigeria. Archives of Medicine and Health Sciences, Volume 5, Issue 1, January-June 2017. pp 46. DOI:10.4103/amhs.amhs_1_17.

Graber M. L. (2013). The Incidence of Diagnostic error in Medicine. RTI International, SUNY Stony Brook School of Medicine, 1 Breezy Hollow, St James, NY 11780, USA;mgraber@rti.org pp 21, doi:10.1136/bmjqs-2012- 001615. http://www.qualitysafety.bmj .com /content/qhc/22/Suppl_2/ii21.full.pdf Retrieved 23/09/2017

Hassan, N., Sayed, O. R., Khalil, A. M., \& Ghany, M. A. (2017). Fuzzy Soft Expert System in Prediction of Coronary Artery Disease. International Journal of Fuzzy Systems, 19(5), 1546-1559. DOI: $10.1007 / \mathrm{s} 40815-016-0255-0$

Josephine M.S. and Jeyabalaraja V. (2012), Expert System and Knowledge Management for Software Developer in Software Companies. International Journal of Information and Communication Technology Research. Volume 2 No.3, March 2012, ISSN 2223-4985. In Chefi Ketata, Maria C. Rockwell and Denis Riordan, "Development of Expert Systems for Stream Sampling in Mineral Processing Plants", Artificial Intelligence in Engineering,14:2, 2000.

Kajal Dhirajlal Chhaganlal (2014). Diagnosis and Differential Diagnosis of Meningitis at Patient's Bed side Using Urine Reagent Strip to Evaluate Cerebro spinal Fluid a Strategy for Early Diagnosis and Treatment. Unpublished doctoral dissertation, Medical Faculty of Ludwig-Maximilians-Universität, Munich, Germany.

Kaur A. and Bhardwaj A. (2014), Genetic Neuro Fuzzy System for Hypertension Diagnosis. (IJCSIT) International Journal of Computer Science and Information Technologies, Vol. 5 (4), pp.4986-4989.

Kaur R. and Kaur A. (2014), Hypertension Diagnosis Using Fuzzy Expert System. International Journal of Engineering Research and Applications (IJERA) ISSN:2248-9622.pp 14-18

Kawasaki A. and Purvin V.A. (2002), Photophobia as the presenting visual symptom of chiasmal compression. J Neuroophthalmol. 2002; 22:3-8. [PubMed: 11937897] cited in Digre K.B. and Brennan K.C. (2012), Shedding light on photophobia. $J$ Neuroophthalmol.2012;32(1): pp 68-81. doi:10.1097/WNO.0b013e3182474548

Kelley D. (2014). Heart Disease: Causes, Prevention, and Current Research. Johnson County Community College. JCCC Honors Journal Volume 5 Issue 2 Spring 2014 Article 1.

Krishna Anand S, Kalpana R and Vijayalakshmi S. (2013), Design and Implementation of a Fuzzy Expert System for Detecting and Estimating the Level of Asthma and Chronic Obstructive Pulmonary Disease. World Applied Sciences Journal 23 (2): 213-223, 2013, ISSN:1818-4952@IDOSI Publications, 2013, DOI:10.5829/idosi.wasj. 2013.23.02. 13046

Krysta Peterson, Meningococcal Meningitis. http://www.austincc.edu/microbio/2704w/nm. htm retrieved $14 / 09 / 2017$

Lafta H.A. and Oleiwi W. K. (2017), A Fuzzy Petri Nets System for Heart Disease Diagnosis. Journal of Babylon University/Pure and Applied Sciences/No.(2)/Vol.(25): 2017. retrieved on 01/11/2017

Mackowiak P. (2005). Temperature regulation and pathogenesis of fever. Mandell, Douglas and Bennett's Principles and practise of infectious disease, vol. 1, 6th edition Elsevier Churchill Livingstone; pp. 703-718. Cited in Ogoina Dimie (2011), Fever, fever patterns and diseases called 'fever'. A review. Journal of Infection and Public Health (2011) 4, 108-124.

Manchanda V, Gupta S, Bhalla P. (2006), Meningococcal Disease: History, Epidemiology, Pathogenesis, Clinical Manifestations, Diagnosis, Antimicrobial Susceptibility and Prevention.Indian Journal of Medical Microbiology, (2006) Vol.24 (1):7-19. Retrieved 12/9/2017. 
Mamta Baheti (2016), Study of Need and Framework of Expert Systems for Medical Diagnosis. IOSR Journal of Computer Engineering (IOSR-JCE) e-ISSN: 2278-0661, p-ISSN: 2278-8727 PP 45-48.

Mankar N.B. and Nagdeve U.T. (2014). Analysis of Ulcer Wound Using Fuzzy Logic. International journal of engineering sciences \& research Technology, Mankar, 3(9): September, 2014. ISSN: 2277-96557:16

Mayilvaganan M and K.Rajeswari. (2014), Human Blood Pressure Classification Analysis Using Fuzzy Logic Control System in Datamining. International Journal of Emerging Trends \& Technology in Computer Science (IJETTCS). Volume 3, Issue 1, January - February 2014, ISSN 2278-6856. Pp: 305 - 306.

Mostafa L, Esmat K, Hassan K, Mehrdad F and Mahdi E. (2015). A Fuzzy Expert System for Distinguishing between Bacterial and Aseptic Meningitis. Iranian Journal of Medical Physics. Vol. 12, No. 1. Winter 2015, Pp: 1-6.

Murthy R., Pavlidis I., and Tsiamyrtzis P.(2004) “Touchless Monitoring of Breathing Function,” Proceeding of the 26th Annual International Conference of the IEEE EMBS. Pp. 1196-1199.

Ogoina D. (2011), Fever, fever patterns and diseases called 'fever'. A review: Journal of Infection and Public Health (2011) 4, 108-124.

Olawale G \& Orogun G. (2017), One doctor still attends to 6,000 patients in Nigeria. https://www.vanguardngr.com/2017/01/one-doctor-still-attends-6000-patients-nigeria-don/ . Retrieved 28/11/2017.

Olayanju T.A. (2017). Introduction to Expert Systems. National Open University of Nigeria Lecture outline: Retrieved from: http://nouedu.net/sites/default/files/2017-03/CIT474.pdf on 27/08/2018.

Priynka S, Singh DBV, Manoj K. B and Nidhi M(2013), Decision Support System for Malaria and Dengue Disease Diagnosis (DSSMD). International Journal of Information and Computation Technology. ISSN 0974-2239 Volume 3, Number 7 (2013), pp. 633-640 @ International Research Publications House.

Rho J. M., Sankar R. and Stafstrom C. E., (2010), Epilepsy: Mechanisms, Models, and Translational Perspectives. CRC Press Taylor \& Francis Group 6000 Broken Sound Parkway NW, Suite 300 Boca Raton, FL 33487-2742. ISBN: 978-1-4200-8559-4.

Santosh K. P, Dipti P.S. and Indrajit M. (2010). An Expert System for Diagnosis of Human Diseases. 2010 International Journal of Computer Applications (0975 - 8887) Volume 1 - No. 13.

Senthil Kumar A.V., Diagnosis of heart disease using Advanced Fuzzy resolution Mechanism (2013), International Journal of Science and Applied Information Technology (IJSAIT),Vol.2, No.2, Pages : 22-30 (2013), Special Issue of ICCTE 2013 - Held during 11-12 March, 2013 in Hotel Crowne Plaza, Dubai, ISSN 2278-3083.

Singh H, Madan M. G, Thomas M, Zeng-Guang H, Kum K. G, Ashu, Solo M. G. and Zadeh L.A. (2013). RealLife Applications of Fuzzy Logic. Hindawi Publishing Corporation, Advances in Fuzzy Systems, Volume 2013, Article ID 581879, 3pages, http://dx.doi.org/10.1155/2013/581879

Smita S. S., Sushil S. and Ali M. S. (2013), Generic Medical Fuzzy Expert System for Diagnosis of Cardiac Diseases. International Journal of Computer Applications (0975 - 8887), Volume 66- No.13, March 2013, Pp. 35-44.

Suleiman D E (2016). The persistent problem of diagnostic errors. Annals of Nigerian Medicine|Published by Wolters Kluwer - Medknow. 2016, 10:1-2. www.anmjournal.com, DOI: $\quad$ 10.4103/03313131.189800.

Vijay K. M, Ravinder M., Ryan W, and Elpiniki I P.(2012), Supporting meningitis diagnosis amongst infants and children through the use of fuzzy cognitive mapping. Mago et al. BMC Medical Informatics and Decision Making 2012, 12:98. 
Wan Hussain, Wan Ishak and Fadzilah Siraj, (2017) Artificial intelligence in medical application: An exploration. P.1

http://citeseerx.ist.psu.edu/viewdoc/download;jsessionid=36890431BE25EB5E5D92B30A2CEDF318d oi=10.1.1.102.4631 \&rep= rep1\&type $=$ pdf retrieved 23/10/2017.

Wang W.C., Ahmed A and Hunter A. (2006), Vision Analysis in Detecting Abnormal Breathing Activity in application to Diagnosis of Obstructive Sleep Apnoea. EMBS Annual International Conference New York City, USA, Aug 30-Sept 3, 2006. Pp. 4469 - 4473.

William K. (2018). When body temperature is low. Harvard Health publishing, Harvard Medical School. https://www.health.harvard.edu/staying-healthy/when-is-body-temperature-too-lowPublished: January, 2018.

World Health Organization, WHO record of Meningitis cases 2017 http://www.who.int/emergencies/nigeria/meningitis/en/ retrieved 16/9/2017.

Wu Y., Duana H. and Duc S. (2015), Multiple fuzzy c-means clustering algorithm in medical diagnosis. Technology and Health Care 23 (2015) S519-S527 S519 DOI10.3233/THC-150989. IOS press.

Yilmaz M. (2015). Evaluation of Total Antioxidant Capacity (TAS) by Using Fuzzy Logic. British Journal of Mathematics \& Computer Science 8(6): 433-446, 2015, Article no. BJMCS.2015.176 ISSN: 22310851.

Yiwen W. and Mark H. (2017), Photophobia in neurologic disorders. Wu and Hallett Translational Neurodegeneration (2017) 6:26. DOI 10.1186/s40035-017-0095-3

Yuan G., Drost N.A. and McIvor R.A. (2013), Respiratory Rate and Breathing Pattern. Clinical Review. McMaster University Medical Journal. Volume 10 No. 1, 2013. pp 23-25.

Zirra P.B, Umar T.M and Wallace E. O.(2016), A Fuzzy Based System for Determining the Severity Level of Osteomyelitis. International Journal of Advanced Research in Computer Science and Software Engineering 6(6), June- 2016, pp. 174-183.

Zadeh L. A. (1975). The Concept of a Linguistic Variable and its Application to Approximate Reasoning-I. Information sciences. American Elsevier Publishing Company, Inc., pp. 199-248. 